\title{
UTILIZATION TREND OF WOOD SPECIES UTILIZED IN FURNITURE INDUSTRY IN SELECTED CITIES IN NIGERIA
}

\author{
AROWOSOGE O.G.E ${ }^{1 *}$, O.Y. OGUNSANWO ${ }^{2}$ AND LABODE POPOOLA ${ }^{2}$ \\ ${ }^{1}$ Department of Forestry, Wildlife and Fisheries Management, University of Ado-Ekiti, \\ Nigeria. \\ ${ }^{2}$ Department of Forest Resources Management, University of Ibadan. Nigeria. \\ *E-mail: yemisoge@yahoo.co.uk.
}

\begin{abstract}
The utilization trend of four commonly used wood species and two lesser used wood species that are used for furniture making was examined. The wood species are Mansonia altissima (Mansonia), Khaya ivorensis (Khaya), Cordia millenii (Cordia) and Tectona grandis (Teak) as commonly used wood species; Aningeria robusta (Aningeria) and Gmelina arborea (Gmelina) as lesser used wood species. 154 small-scale furniture factories (SSFF), 28 medium-scale furniture factories (MSFF) and 11 large-scale furniture factories (LSFF) selected through stratified random sampling procedure in Lagos, Ibadan and Benin cities were considered for the study. The quantity (cubic meter) of the six wood species used in making interior furniture such as chair, table, bed cabinet, shelf, wardrobe cupboard and settee from 2001 to 2006 was obtained through a structured questionnaire. The study revealed that in SSFF, the utilization of Khaya, Cordia, Aningeria and Gmelina had been on the increase from year 2001 to 2006 while the trend for Mansonia and Teak did not follow a definite pattern. For MSFF, the trend showed that utilization of Khaya and Cordia increased from 2001 to 2004 and thereafter declined while that of Mansonia and Teak did not follow a definite trend for the 6 years considered for the study. However, Aningeria and Gmelina increased yearly from 2001 to 2006. For LSFF, no definite trend was observed in the utilization of Mansonia, Khaya, Cordia and Teak while Aningeria and Gmelina also increased yearly for the 6 years. The trend for the total wood utilization by the SSFF, MSFF and LSFF showed that Khaya was mostly used by the three scales of furniture industry, followed by Cordia while the utilization of Teak by the three scales of furniture industry was low for the six years of study. There is urgent need for a massive plantation establishment of Teak and Gmelina.
\end{abstract}

Keywords: Utilization, wood species, furniture industry.

\section{INTRODUCTION}

The Nigerian forest estate occupies $10.2 \%$ (10,006,200 hectares) of the country land mass of 98,321,300 hectares (Aruofor, 2001) and it has been the source of the wood species used for wooden furniture and other wooden construction in Nigeria. This forest has a mixture of diverse timber species estimated to about 600 species (Beak Consultants, 1999). Apart from sustaining the domestic markets, this forest has been under pressure as early as 1930s when the Nigerian timber became known at the international market. In order to satisfy both the domestic and the external markets, exploitation of the forest was intensified and became largely unregulated. Following the large quantity of the wood species that was exploited, Nigeria ranked $2^{\text {nd }}$ in tropical wood export in Africa (Adeyoju, 1975) and until early 1970s, wood export was a major source of foreign exchange for the country. By the middle of 1970s, the forest has been highly degraded and could no longer sustain both the domestic and international markets. Hence, the exportation of roundwood and semi-finished products were banned in 1976 by the Federal Government of Nigeria. Nevertheless, with increasing population, rising standard of living and an increase in the number of wood 
processing industries in the country, the domestic demand for wood continued to increase. Thus in the last two decades, there has been a large gap in the supply-demand trend of the wood-based industries for wood raw material as a result of the inability of the hitherto endowed forests to sustain the industries. FAO (2000) has reported the production and consumption trends of wood and wood products in Nigeria for 1980 and 1995 with projection up to 2015 as contained in Table 1.

Table 1: Production and consumption trends of wood and wood products in Nigeria (1980 and 1995) with projection to 2015

\begin{tabular}{|c|c|c|c|c|c|c|c|c|c|}
\hline \multirow[t]{2}{*}{ Wood form } & \multicolumn{3}{|c|}{ Production ('000m ${ }^{3}$ ) } & \multicolumn{3}{|c|}{ Consumption $\left({ }^{6} 000 m^{3}\right)$} & \multicolumn{3}{|c|}{ Balance ('000m³) } \\
\hline & 1980 & 1995 & 015 & 1980 & 1995 & 015 & 1980 & 995 & 2015 \\
\hline $\begin{array}{l}\text { Industrial } \\
\text { roundwood }\end{array}$ & 7360 & 8263 & 9718 & 7350 & 8262 & 9816 & 10 & 1 & -98 \\
\hline Sawnwood & 2794 & 2723 & 3145 & 2752 & 2706 & 3190 & 42 & 17 & -45 \\
\hline $\begin{array}{l}\text { Wood based } \\
\text { panel }\end{array}$ & 116 & 112 & 113 & 285 & 115 & 153 & -169 & -3 & -40 \\
\hline $\begin{array}{l}\text { Veneer sheets } \\
\text { and plywood }\end{array}$ & 45 & 40 & 10 & 50 & 41 & 46 & -5 & -1 & -36 \\
\hline Particle board & 0 & 0 & 0 & 95 & 3 & 5 & -95 & -3 & -5 \\
\hline
\end{tabular}

(Source: Adapted from FAO, 2000)

From Table 1, it is obvious that sawnwood whose production level for 1980 stood at $2,794,000 \mathrm{~m}^{3}$ had a consumption level of $2,752,000 \mathrm{~m}^{3}$ in the same year, a difference of $42,000 \mathrm{~m}^{3}$ of excess production. However, by 1995 , the difference had been narrowed down to $17,000 \mathrm{~m}^{3}$. A projection of this trend into year 2015 brings the difference between production and consumption to $-45,000 \mathrm{~m}^{3}$. That is, projected consumption is $45,000 \mathrm{~m}^{3}$ higher than projected production; meaning that if care is not taken, Nigeria may be unable to meet her domestic needs for wood production by year 2015 and beyond. This negative trend is similar for all the wood forms/products (industrial roundwood, wood-based panel, veneer sheets and plywood and particle board) analyzed by FAO as indicated in the table. Hence, the rate of loss, if not checked may create a serious deficit especially for the furniture industry in Nigeria.

A study of the land use change in Nigeria between 1978 and 1995 showed deforestation at an alarming rate of between 3\% and 5\% (Beak Consultants, 1998). Similarly, in South Western Nigeria, the annual average rate of deforestation was estimated to be $3.5 \%$ (Adeofun and Akinsanmi, 1997). With the extensive depletion of the forest, Adeyoju (2001) observed that the total forest cover (disturbed and undistured) which was $10 \%$ of the total land area in 1976 is now less than 6\%. Currently, Amiebenomo (2003) considered only about 130,446 hectares $(1.2 \%)$ of the $10,006,200$ hectares of the forest estate in Nigeria as undisturbed.

With the high rate at which the forest is being degraded, it is pertinent to know that only few wood species are exploited for both domestic and international markets. According to Beak Consultants (1999), of the 600 total known wood species which abound in the Nigerian forest, only 60 wood species have been found to be of market value while others are neglected or destroyed during harvesting. The furniture industry is conservative in the wood species utilized for furniture generally and thus concentrates on the use of few of these 60 wood species that have been found to be of market value. In prioritizing the wood species 
utilized for furniture making, Arowosoge (2006) obtained 33, 28 and 18 wood species as wood used for furniture making in Lagos, Ibadan and Benin respectively. From the three cities, 39 wood species were compiled. These 39 wood species constitute only $7 \%$ of the total known Nigerian forest tree species and $65 \%$ of the marketable wood species. The study further classified 15 of these 39 wood species as commonly used wood species while the remaining 24 were classified as lesser used species. The implication of this is that 15 of the 600 total known wood species that abound in the Nigerian forest are preferred for furniture making. Consequently these preferred commonly used wood species have declined both in quantity and quality (Beak Consultants, 1998) due to the extensive depletion of the forest. This justifies the reason for research on the utilization trend of the wood species used for furniture making in Nigeria. The study provides the pattern of wood species utilized for furniture making and develops the basis for wood species production for furniture making.

\section{METHODOLOGY}

Stratified random sampling procedure was used to select $35 \%$ of the 551 registered furniture factories in Lagos, Ibadan and Benin cities. Consequently, a total of 114 Furniture Factories (FF), comprising 86 SSFF, 20 MSFF and 8 LSFF were studied in Lagos while 40 FF comprising 35 SSFF, 3 MSFF and 2 LSFF were studied in Ibadan. In Benin, a total of 39 FF comprising 33 SSFF, 5 MSFF and 1 LSFF were also studied. This made a total of 193 furniture factories comprising of 154 small, 28 medium and 11 large scale. The purposive selection of Lagos, Ibadan and Benin considered for the study was guided by the relative abundance of FF in the cities. The cities have a lot in common, such as tropical rainforest that are endowed with timber resources in varying degrees with distinct wet and dry seasons. The wet season begins in March and ends in November, but intensive rainfall lasts from April to October while dry season lasts from December to February. Mean annual rainfall and temperature range from 1500 to $2500 \mathrm{~mm}$ and $21^{\circ} \mathrm{C}$ to $31^{\circ} \mathrm{C}$ respectively while humidity varies between 35 and 80\% (Agboola,1979).

The wood species studied are Mansonia, Khaya, Cordia and Teak classified as the top four commonly used wood species for furniture making. Aningeria and Gmelina that are evolving and were not in use in Benin, were also studied as lesser used wood species (Arowosoge, 2006). The quantities (in cubic meter) of the six wood species used in making interior furniture such as chair, table, bed cabinet, shelf, wardrobe cupboard and settee from 2001 to 2006 were obtained from the FF in the study area. Data were also collected on the sources and availability of the six wood species. Data collected were collated and analysed using descriptive analysis of tables, line graph and bar chart.

\section{RESULTS AND DISCUSSION Wood utilization trend}

The wood utilized in cubic meter per annum by SSFF, MSFF and LSFF are presented in Table 2. The utilization trend for SSFF as shown in Figure 1 reveals that the utilization of Khaya, Cordia, Aningeria and Gmelina had been on the increase from 2001 to 2006. The yearly increase in the wood species utilized was however not outrageous but that of Khaya was most pronounced when compared with others. The trend for Mansonia and Teak did not follow a definite pattern. For MSFF, the trend shows that utilization of Khaya and Cordia increased from 2001 to 2004 and thereafter declined while that of Mansonia and Teak did not follow a definite trend for the 6 years. However, Aningeria and Gmelina increased yearly at a low pace from year 2001 to year 2006 (Figure 2). For LSFF, Figure 3 shows that no definite trend was observed in the utilization of Mansonia, Khaya, Cordia and Teak while Aningeria and Gmelina followed the same trend observed for SSFF and MSFF as their utilization increased yearly for the 6 years. 
The yearly increment observed for Aningeria and Gmelina in the three scales of furniture industry, despite the fact that they were not utilized in Benin, shows that the two species are gaining increasing prominence in the furniture industry. Reasons may be due to their relative abundance and their relatively low prices. The irregular pattern observed in other wood species utilized by the MSFF and LSFF could be due to dwindling supply of wood raw material and the high prices at which they were sold.

The trend for the total wood utilization by the SSFF, MSFF and LSFF (Figure 4) shows that Khaya was mostly used by the three scales of furniture industry followed by Cordia. In MSFF and LSFF the use of Cordia was followed by Mansonia. In SSFF the use of Cordia was followed by Aningeria and Gmelina while the use of Mansonia was relatively low. The low utilization of Mansonia by the SSFF could be attributed to its relative high prices. Moreso, that the major consumers of the furniture produced by this SSFF were low income earners who could not afford to purchase high priced furniture. The situation is such that SSFF only made use of Mansonia based on request of consumers. As a matter of fact it is hard to see furniture made from Mansonia being displayed by SSFF. The trend observed for the utilization of Teak by the three scales of furniture industry was low for the six years of study. The low level of utilization was due to scarcity of the standard dimension of the planks in the market in recent years as claimed by the respondents. The few planks that were available were of shorter width of $15.24 \mathrm{~cm}$ and $10.16 \mathrm{~cm}$ due to short rotation rather than the standard size of $30.48 \mathrm{~cm}$ and which the furniture makers believed were not of good technical properties.

The current acute shortage of Teak is pathetic and it could have been avoided, moreso that Ojo (1977) had anticipated this shortage to start as far back as year 2000 in Nigeria and recommended the establishment of a massive plantation programme of about 30,000 hectares annually for a period of forty years in order to meet timber requirement of the nation. Umeh (2005) reported the total area of plantation established for Gmelina and Teak between 1970 and 1984 to be 82,434 hectares. In 1998, a Forestry Resources survey estimated the plantation of Gmelina and Teak within the reserves and in off-reserve areas in Nigeria to be 196,008 hectares and 704 hectares respectively. However, a re-survey in 2004 showed that the teak plantations have been completely clear felled without replanting or any other form of forest management (FORMECU,1999). This situation shows that the government's disposition in providing wooden raw material for the country has consistently been on the negative sides. This is because Teak has been found to be associated with ease of establishment, fast growth rate, fire resistance traits and excellent wood properties (Akinsanmi, 1985). These attributes, coupled with the findings of Beak Consultants (1998) that timber size with annual harvest of $464 \mathrm{~m}^{3}$ per hectare could be obtained from Teak with a rotational age of 30 years on a class one site, further suggest that it should be in abundance for the country's consumption. Besides, it should be a wood to look up to as a substitute to other fast disappearing commonly used wood species, moreso that it ranked $4^{\text {th }}$ as one of the most preferred commonly used wood species for furniture making (Arowosoge, 2006).

The total wood utilized per annum by the SSFF studied ranged from $5350.6 \mathrm{~m}^{3}$ to $7639.2 \mathrm{~m}^{3}$ in an increasing order from 2001 to 2006 while the average utilized per annum, per industry ranged from $34.7 \mathrm{~m}^{3}$ to $49.6 \mathrm{~m}^{3}$. For MSFF studied, the total wood utilized from 2001 to 2006 ranged from $20255.8 \mathrm{~m}^{3}$ to $23214.0 \mathrm{~m}^{3}$ with an average range of between $723.4 \mathrm{~m}^{3}$ and $829.1 \mathrm{~m}^{3}$ per annum per industry. The total wood utilized per annum by the LSFF ranged from $12089.6 \mathrm{~m}^{3}$ to $13689.4 \mathrm{~m}^{3}$ with an average range of between $1099.1 \mathrm{~m}^{3}$ and $1244.5 \mathrm{~m}^{3}$ per annum per industry (Table 2). The irregular pattern observed for Mansonia, Khaya, Cordia, and Teak utilized by MSFF and LSFF for the six years of study could be due to problems encountered during production such as epileptic power supply, non-functioning 
Journal of Agriculture and Social Research (JASR) VOL. 10, No. 2, 2010

of machines/equipment which atimes reduced the productivity of the industry and the dwindling supply of wooden raw material.

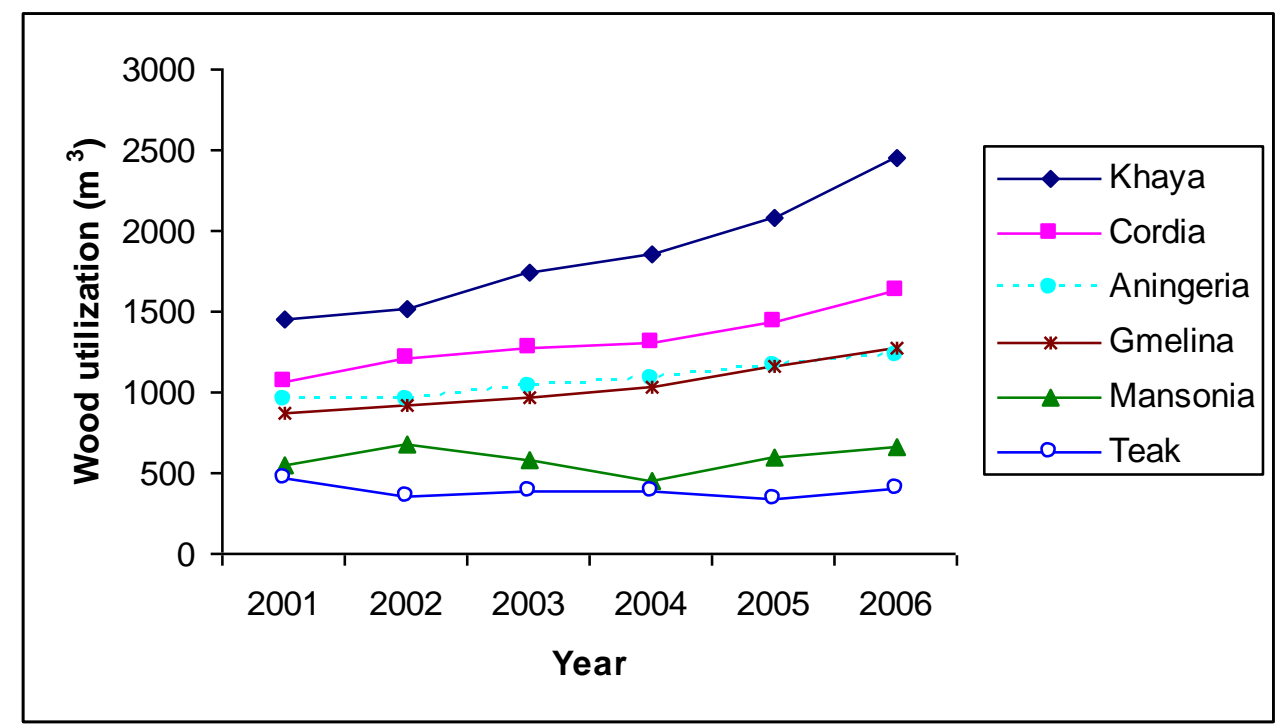

Figure 1: Wood utilization trend for Small Scale Furniture Factories

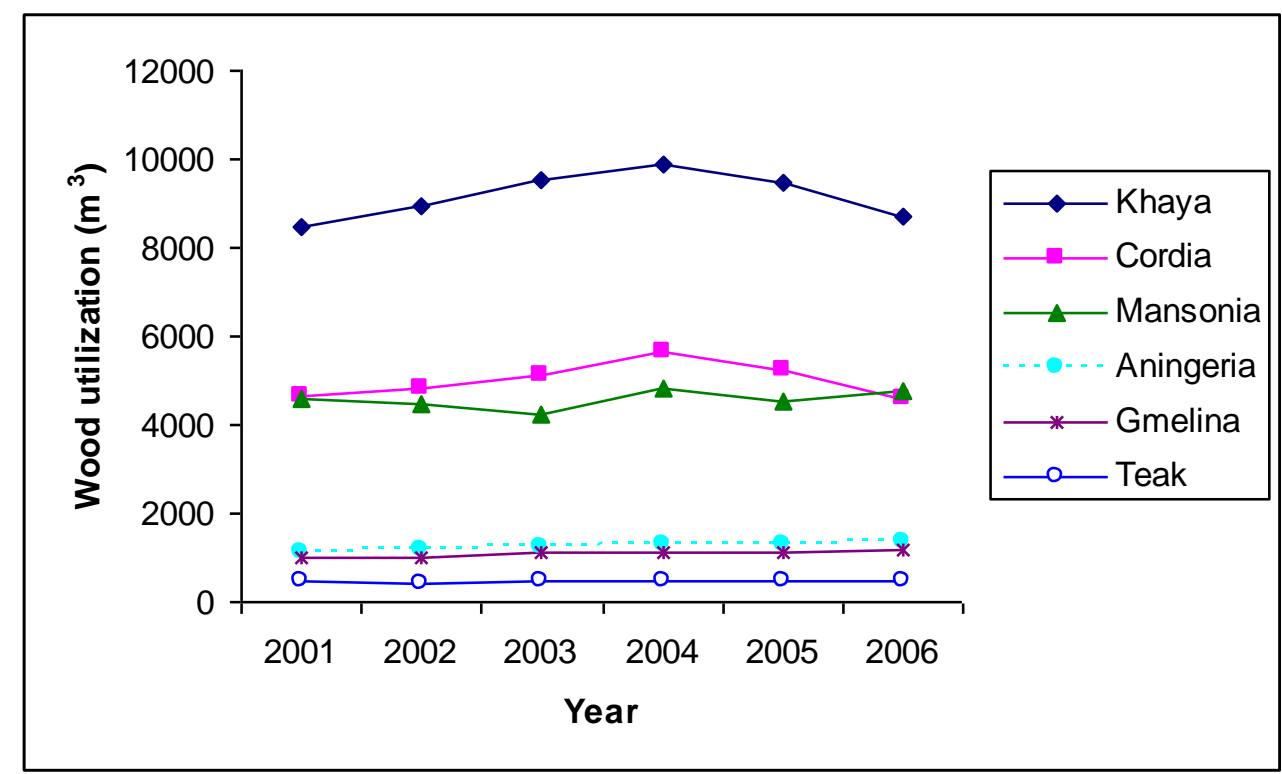

Figure 2: Wood utilization trend for Medium Scale Furniture Factories 
Journal of Agriculture and Social Research (JASR) VOL. 10, No. 2, 2010

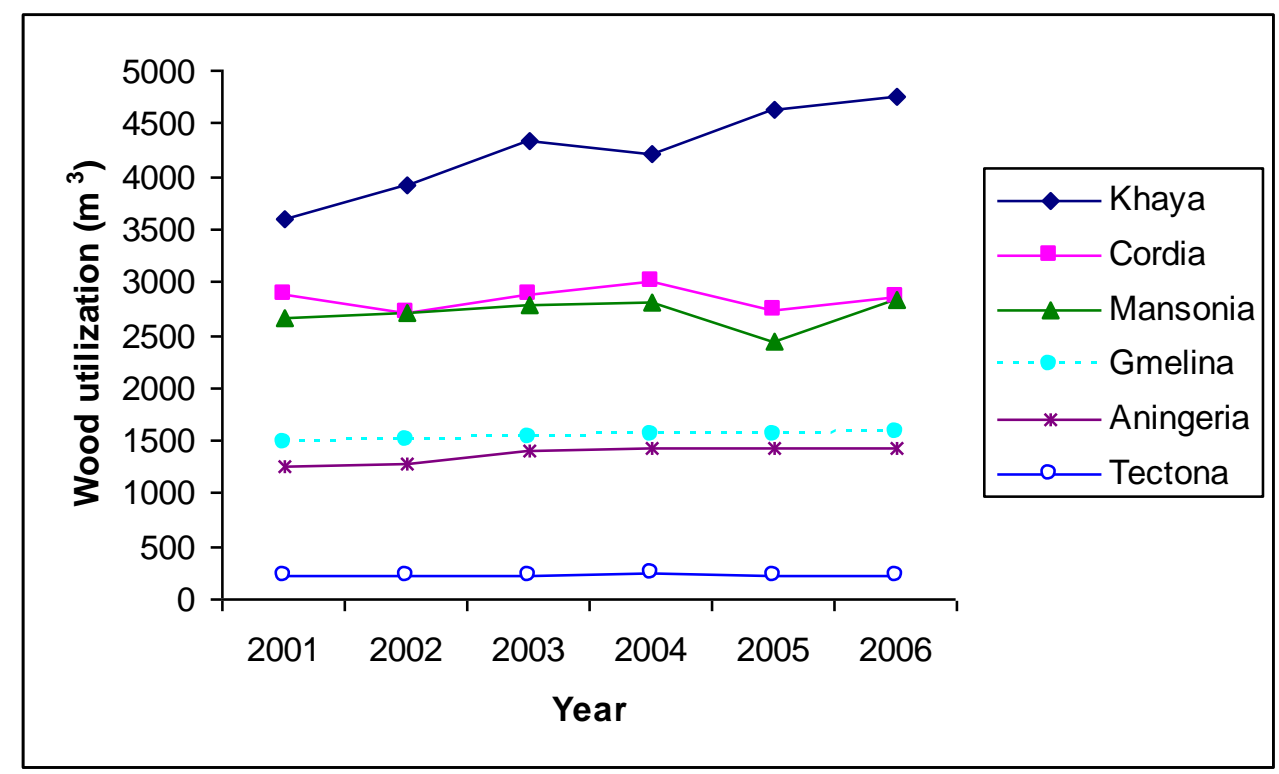

Figure 3: Wood utilization trend for Large Scale Furniture Factories

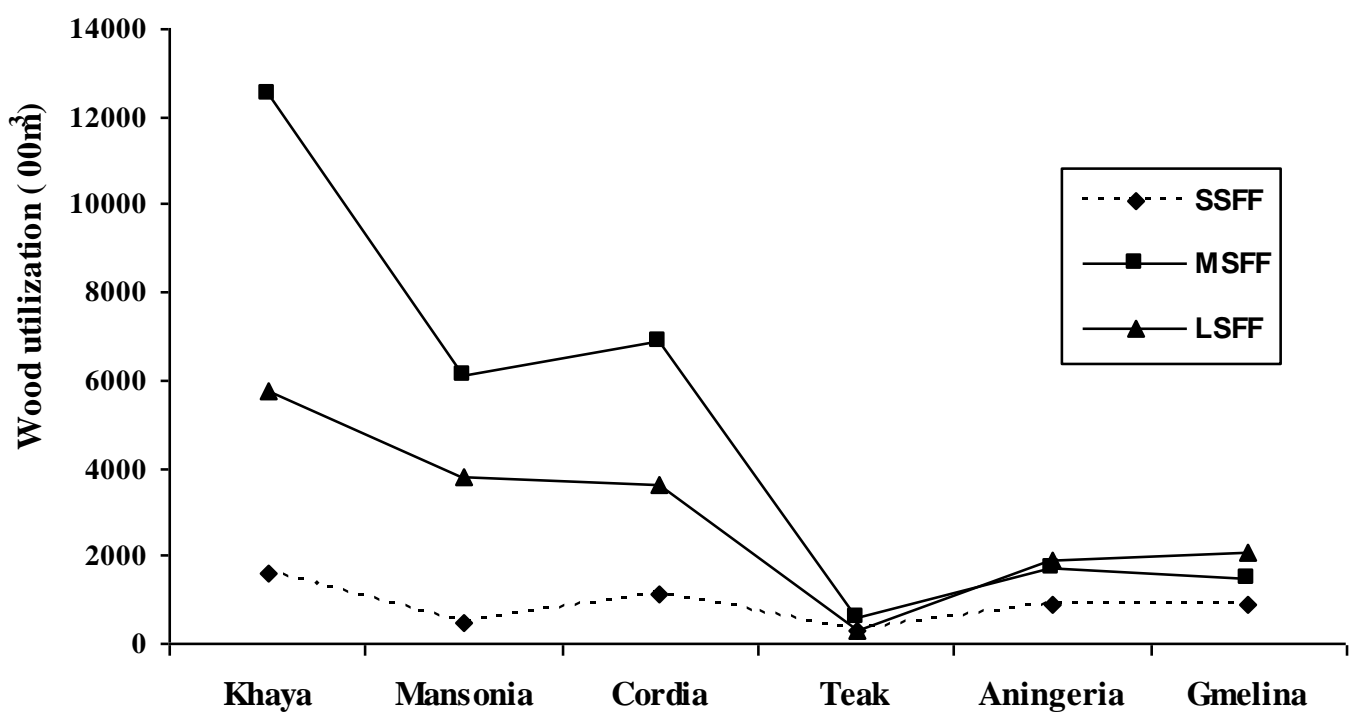

Figure 4: Wood utilization trend for the three scales of furniture industry 


\section{Wood utilization trend for the top four furniture items produced by SSFF, MSFF and LSFF}

The utilization trends of Mansonia, Khaya, Cordia, Teak, Aningeria, and Gmelina for the top four furniture items (chairs, tables, beds and wardrobes) produced by the SSFF, MSFF and LSFF are as shown in figures 5 to 7. For SSFF, Khaya, Cordia, Aningeria, and Gmelina were equally utilized for the production of the four furniture items. Mansonia and Teak were mainly used for chairs and tables, followed by bed while wardrobe had the least utilization (Figure 5). The trends observed for the utilization of Mansonia, Khaya, Cordia, Aningeria, and Gmelina for the top four furniture items produced by MSFF and LSFF were the same. Khaya was equally used for all the furniture items. Mansonia and Teak were utilized mainly for chairs and tables, followed by wardrobe while bed had the least utilization. Cordia was utilized mainly for bed and wardrobe, followed by tables and chairs. Aningeria and Gmelina were used mainly for chairs and tables, followed by wardrobe while bed had the least utilization for Aningeria. However, Gmelina was not utilized for bed making by both MSFF and LSFF (Figures 6 and 7).

The uniform utilization of Khaya, Cordia, Aningeria and Gmelina for all the furniture items produced by the SSFF was due to the less attention given to the technical properties of the wood species utilized for the different furniture items as observed during the course of this study. On the other hand, the MSFF and LSFF claimed to utilize wood species based on their technical and aesthetic properties. Hence in selecting wood species for a particular purpose, the value of aesthetical properties such as colour, texture, grain pattern are evaluated along with the influence of technical properties such as shrinkage and strength. The non utilization of Gmelina for bed was therefore due to its high shrinkage which according to MSFF and LSFF results in dimensional changes and on the long run, loosening of joints during seasonal changes in relative humidity and temperature. The use of wood in service is generally linked with shrinkage of the wood. Reason been that shrinkage and movement of wood have been found to be highly correlated. Thus, timber with low movement values is always in demand for high quality joinery work, paneling and domestic flooring as timber with high movement values results in loosening of joints and in the development of unsightly gaps (Desch, 1983; Dinwoodie, 1989).

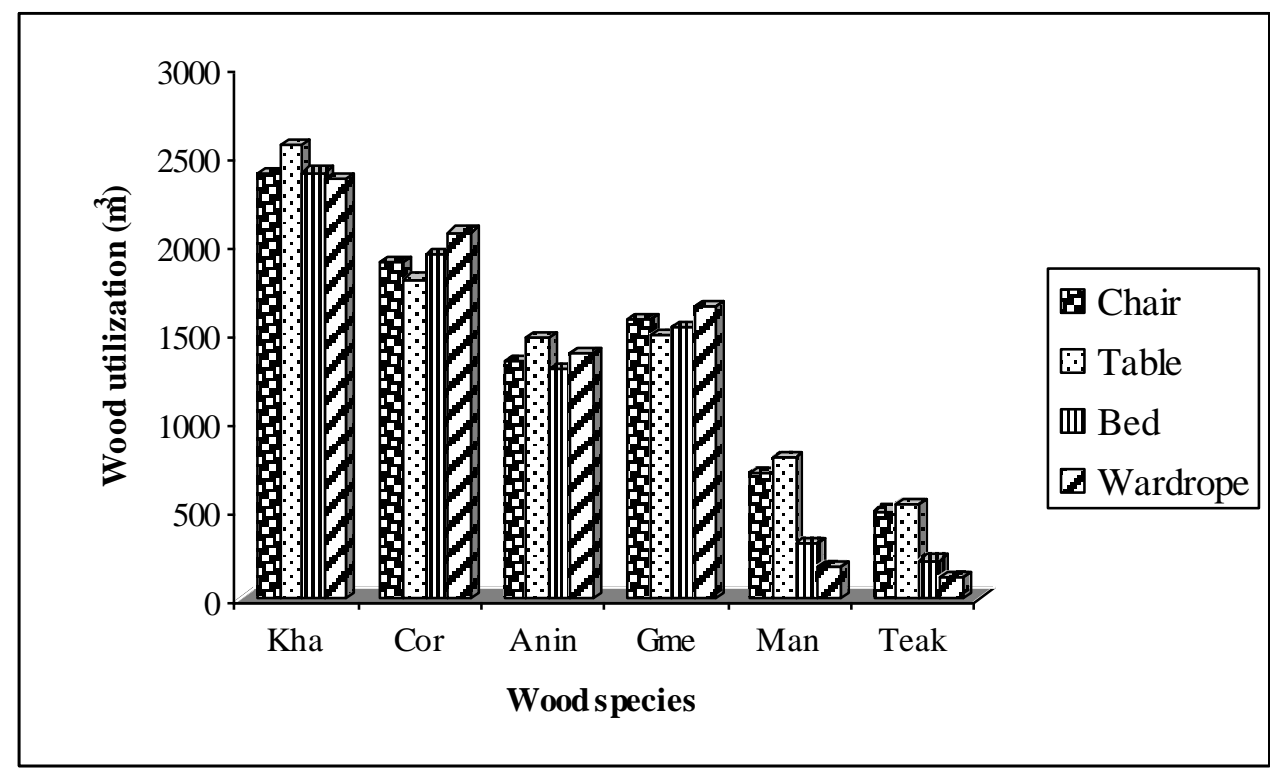

Note: $\mathrm{Kha}=($ Khaya $)$, Cor $=($ Cordia $)$, Anin $=($ Aningeria $)$, Gme $=($ Gmelina $)$

Man $=($ Mansonia $)$ 
Figure 5: Wood utilization for different furniture types by Small Scale Furniture Factories

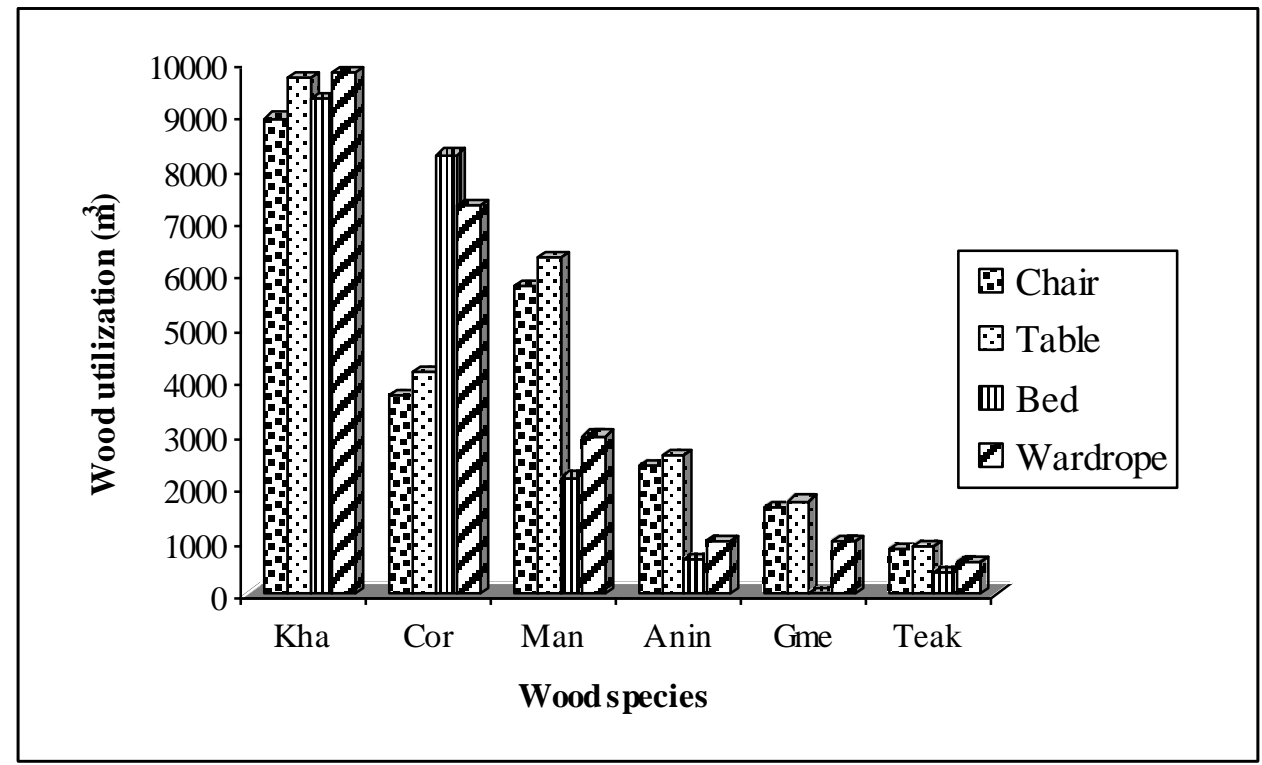

Note: $\mathrm{Kha}=($ Khaya $)$, Cor $=($ Cordia $)$, Man $=($ Mansonia $)$, Anin $=($ Aningeria $)$, Gme $=($ Gmelina $)$

Figure 6: Wood utilization for different furniture types by Medium Scale Furniture Factories

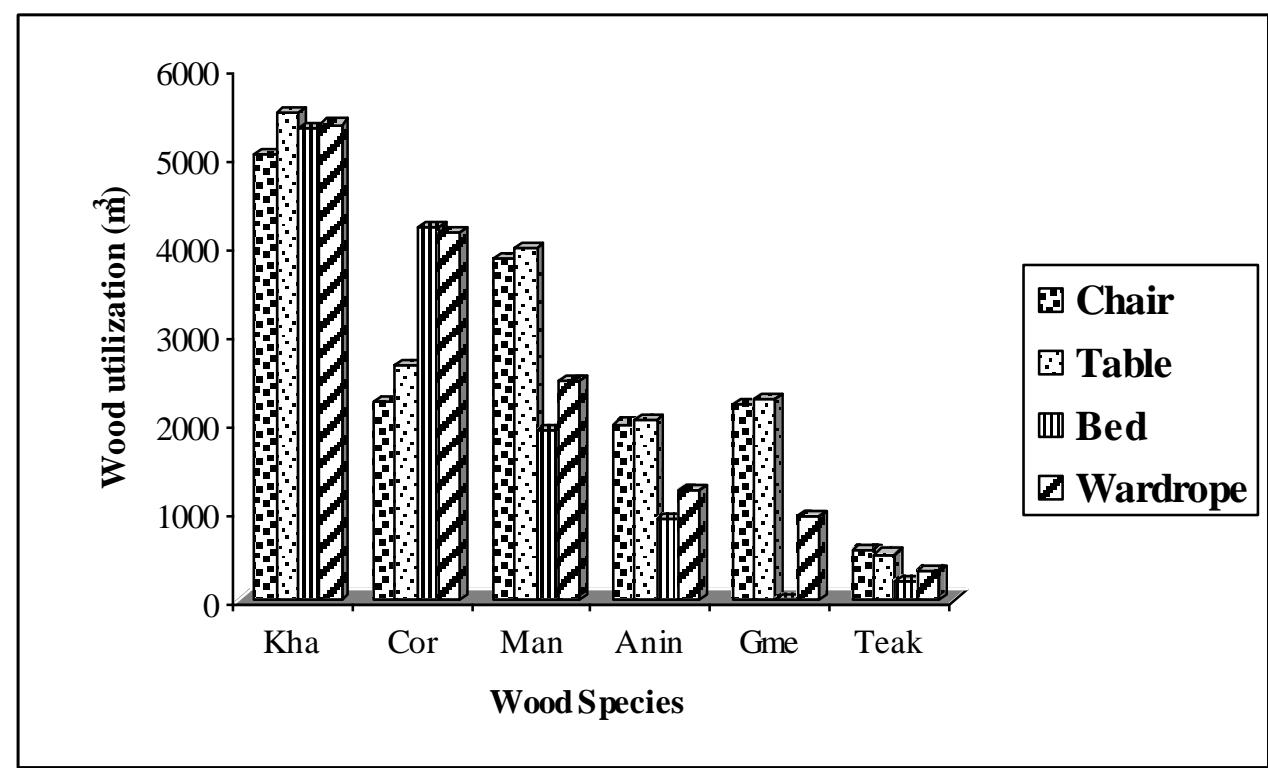

Note: Kha $=($ Khaya $)$, Cor $=($ Cordia $)$, Man $=($ Mansonia $)$, Anin $=($ Aningeria $)$, Gme $=($ Gmelina $)$

Figure 7: Wood utilization for different furniture types by Large Scale Furniture Factories

\section{CONCLUSION}

The irregularity obtained in the utilization pattern of Mansonia, Khaya, Cordia coupled with the low utilization of Teak over a period of six years shows the dwindling 
availability of these wood species. On the other hand, Aningeria and Gmelina are gaining increased prominence in the three scales of furniture industry due to their relative abundance. This is despite the fact that they were not utilized in Benin.

The acute shortage of Teak calls for a massive plantation establishment. There is the urgent need to encourage the private sectors and most especially the wood based sector to pursue vigorously the establishment of Teak plantation to compliment the efforts of government. Similarly, in order to guide against the future scarcity of Gmelina, consideration should also be given to its establishment, since its uses in the three scales of furniture industry has been on the increase, though at a low pace, in two (Lagos and Ibadan) of the three cities studied. Financial incentives in the form of tax relief and provision of long-term loan at low interest rates through financial institutions can serve as a sort of encouragement to wood planters. Other incentives such as free distribution of seedlings can also be provided through the forestry department of each state.

\section{REFERENCES}

Adeofun, C.O. and Akinsanmi, F.A (1997): Assessment in a lowland Area of South West Nigeria using Remote sensing techniques. The Nigeria Journal of Forestry. 27 (1): 1997.

Adeyoju, S.K. (1975): Forestry and the Nigerian Economy. First edition, Ibadan University press. $130 \mathrm{pp}$

Adeyoju, S.K. (2001): Forestry for National Development: A Critique of the Nigerian Situation. Proceedings of the $27^{\text {th }}$ Annual Conference of the Forestry Association of Nigeria, September 2001; Abuja.

Agboola, S.A. (1979): An Agricultural Atlas of Nigeria, Oxford University Press, Nigeria. 248pp.

Akinsanmi, A. (1985): Effect of Rainfall and some Edaphic Factors on Teak growth in Southern -Western Nigeria, Journal of Tropical Forest. Vol.7 Pp 35-39.

Amiebenomo, M.O. (2003): Country paper: Nigeria. In: FAO, 2003. Proceedings of the workshop on tropical secondary forest management in Africa: reality and perspectives. Nairobi, Kenya, 9-13 Dec.2002.

Arowosoge, O.G.E (2006): Prioritization of wood species utilized by furniture industry in some selected cities of Nigeria. Preliminary survey (2006) on Ph.D thesis, University of Ibadan, Nigeria. P 25-32

Aruofor, R. (2001): Nigeria/FAO Forestry outlook studies in Africa, Country Report, FAO Rome. Forestry Paper No. 101.

Beak Consultants and Geomatics International Inc (1998): Forest Resources Study Vol. II, Ondo and Ekiti State Forest Inventory, Management, Planning and Recommendations, FORMECU, Abuja 55pp.

Beak consultants and Geomatics International Inc (1999): Forest resources study, Nigeria: Market Assessment and pricing policies. Report submitted to FORMECU, Abuja. Pp18-19.

Desch, H. E (Revised Dinwoodie J. M.). (1983): Timber: Its Structure, Properties and Utilization. Sixth Edition. Macmillan Press Ltd, London. Pp173-202.

Dinwoodie, J.M. (1989): Wood: Nature's cellular, polymeric fibre composite. A Publication of the Institute of Metals, London: 138pp

FAO (2000): Global Forest Resources Assessment. Global Forest Products Consumption, Production, Trade and Prices. FAO Rome paper 140.

FORMECU, (1999): Forest Resources Study, Nigeria. Revised national report. Vol. 2. Prepared for FORMECU by Beak Consultants and Geomatics International Inc. $224 \mathrm{pp}$ 
Ojo, G.O.A. (1977): Prospects for Development of Industrial Plantation using fast growing Species. Nigerian Journal of Tropical Forestry. 7(2):19-24.

Umeh, W.C. (2005): Trends and impacts of forest plantation development in Nigeria: lessons and prospects. Proceedings of the $30^{\text {th }}$ annual conference of the Forestry Association of Nigeria (FAN) In (ed) Popoola L.P, Mfon and P.I Oni Pp 418-442.

Table 2: Average Wood utilized in $\mathrm{m}^{3}$ from 2001 to 2006 by SSFF, MSFF and LSFF.

\begin{tabular}{|c|c|c|c|c|c|c|c|}
\hline \multirow{3}{*}{$\begin{array}{l}\text { Categor } \\
\mathbf{y} \\
\text { SSFF }\end{array}$} & \multirow[b]{2}{*}{ Wood species } & \multicolumn{5}{|c|}{ Wood utilized in $\mathrm{m}^{3}$ per year } & \\
\hline & & \multirow[t]{2}{*}{2001} & \multirow[t]{2}{*}{2002} & \multirow[t]{2}{*}{2003} & \multirow[t]{2}{*}{2004} & 2006 & \\
\hline & & & & & & & \\
\hline & Mansonia & 550.5 & 675.1 & 575.5 & 453.8 & 595.7 & 665.4 \\
\hline & Khaya & 1455.3 & 1510.3 & 1740.4 & 1855.7 & 2077.7 & 2445.2 \\
\hline & Cordia & 1065.0 & 1210.0 & 1273.1 & 1310.8 & 1435.8 & 1626.2 \\
\hline & Teak & 465.2 & 355.5 & 389.5 & 387.5 & 341.0 & 405.4 \\
\hline & Aningeria & 949.5 & 955.5 & 1034.3 & 1083.3 & 1160.3 & 1221.5 \\
\hline & Gmelina & 865.1 & 925.3 & 966.9 & 1036.0 & 1166.3 & 1275.5 \\
\hline & & $5350.6(15$ & $5631.8(15$ & $5979.6(15$ & $6127.0(15$ & $6776.8(15$ & $7639.2(15$ \\
\hline & Total & 4) & 4) & 4) & 4) & 4) & 4) \\
\hline & Mean & & & & & & \\
\hline & /industry & 34.7 & 36.6 & 38.8 & 39.8 & 44.0 & 49.6 \\
\hline \multirow{10}{*}{ MSFF } & Mansonia & 4563.2 & 4452.1 & 4243.8 & 4819.8 & 4526.7 & 4754.5 \\
\hline & Khaya & 8445.8 & 8952.5 & 9516.2 & 9862.3 & 9480.7 & 8732.3 \\
\hline & Cordia & 4656.0 & 4794.3 & 5103.5 & 5652.2 & 5232.4 & 4615.1 \\
\hline & Teak & 444.1 & 435.4 & 457.6 & 469.1 & 477.9 & 456.2 \\
\hline & Aningeria & 1140.6 & 1176.3 & 1233.2 & 1285.3 & 1293.8 & 1325.9 \\
\hline & Gmelina & 1006.1 & 1013.1 & 1113.6 & 1125.4 & 1142.0 & 1157.2 \\
\hline & & $20255.8(2$ & $20823.6(2$ & $21667.9(2$ & 23214.0 (2 & $22153.5(2$ & 21041.3 \\
\hline & Total & 8) & 8) & 8) & 8) & 8) & 8) \\
\hline & Mean & & & & & & \\
\hline & /industry & 723.4 & 743.7 & 773.9 & 829.1 & 791.2 & 751.5 \\
\hline \multirow{11}{*}{ LSFF } & & & & & & & \\
\hline & Mansonia & 2655.0 & 2706.0 & 2787.1 & 2811.5 & 2443.0 & 2825.6 \\
\hline & Khaya & 3585.4 & 3915.5 & 4325.6 & 4210.5 & 4618.9 & 4755.3 \\
\hline & Cordia & 2886.4 & 2712.0 & 2870.5 & 2992.9 & 2738.6 & 2865.4 \\
\hline & Teak & 222.8 & 210.5 & 233.0 & 234.6 & 226.9 & 232.8 \\
\hline & Aningeria & 1263.6 & 1290.5 & 1401.8 & 1417.4 & 1435.4 & 1422.0 \\
\hline & Gmelina & 1476.5 & 1503.1 & 1534.2 & 1553.9 & 1562.6 & 1588.3 \\
\hline & & $12089.6(1$ & $12337.7(1$ & $13152.3(1$ & $13220.8(1$ & $13025.3(1$ & $13689.4(1$ \\
\hline & Total & 1) & 1) & 1) & 1) & 1) & 1) \\
\hline & Mean & & & & & & \\
\hline & /industry & 1099.1 & 1121.6 & 1195.7 & 1201.2 & 1184.1 & 1244.5 \\
\hline
\end{tabular}

Note: Figures in brackets are the number of furniture firms interviewed.

Source: Field work, (2007) 